\title{
Inferring Soil Moisture Memory from Streamflow Observations Using a Simple Water Balance Model
}

\author{
RENE ORTH \\ Institute for Atmospheric and Climate Science, ETH Zurich, Zurich, Switzerland \\ RANDAL D. KOSTER \\ Global Modeling and Assimilation Office, NASA Goddard Space Flight Center, Greenbelt, Maryland \\ SONIA I. SENEVIRATNE \\ Institute for Atmospheric and Climate Science, ETH Zurich, Zurich, Switzerland
}

(Manuscript received 5 July 2012, in final form 21 June 2013)

\begin{abstract}
Soil moisture is known for its integrative behavior and resulting memory characteristics. Soil moisture anomalies can persist for weeks or even months into the future, making initial soil moisture a potentially important contributor to skill in weather forecasting. A major difficulty when investigating soil moisture and its memory using observations is the sparse availability of long-term measurements and their limited spatial representativeness. In contrast, there is an abundance of long-term streamflow measurements for catchments of various sizes across the world. The authors investigate in this study whether such streamflow measurements can be used to infer and characterize soil moisture memory in respective catchments. Their approach uses a simple water balance model in which evapotranspiration and runoff ratios are expressed as simple functions of soil moisture; optimized functions for the model are determined using streamflow observations, and the optimized model in turn provides information on soil moisture memory on the catchment scale. The validity of the approach is demonstrated with data from three heavily monitored catchments. The approach is then applied to streamflow data in several small catchments across Switzerland to obtain a spatially distributed description of soil moisture memory and to show how memory varies, for example, with altitude and topography.
\end{abstract}

\section{Introduction}

Among the variables of the climate system, soil moisture has potentially important memory (persistence) characteristics. If soil moisture anomalies, as induced by precipitation anomalies, persist into subsequent weeks, and if these long-lasting anomalies are then translated to the atmosphere through their impacts on the surface energy balance, soil moisture memory may have profound implications for climate variability and prediction.

The role of soil moisture memory in climate, however, is still not completely understood. Complexity arises, for example, from the fact that while a soil moisture

Corresponding author address: Rene Orth, Institute for Atmospheric and Climate Science, ETH Zurich, Universitätstr. 16, CH8092 Zurich, Switzerland.

E-mail: rene.orth@env.ethz.ch persistence signal can be translated to the atmosphere through evaporation anomalies (i.e., through soil moisture-evapotranspiration coupling and landatmosphere interactions), these evaporation anomalies in turn act to reduce any original soil moisture anomaly; that is, a soil moisture anomaly, when it affects the surface fluxes, also acts to limit its own lifetime (although positive feedbacks with precipitation could also enhance it; e.g., Koster and Suarez 2001). In considering this balancing act, it is instructive to consider two competing and extreme scenarios. In the first scenario, evaporation processes annihilate a soil moisture anomaly within a day or two of its formation; soil moisture memory would then be small, and its effects on climate variability would necessarily be minimal. In the second scenario, the soil moisture anomaly does not affect evaporation or runoff and thereby persists indefinitely; here again, because the atmosphere or rivers cannot feel the anomaly, impacts on 
climate variability would necessarily be small. Evidence exists to show that neither of these extremes wholly captures the way nature works. In many regions, an important middle ground is achieved: soil moisture anomalies have been observed to persist for weeks to months (Vinnikov and Yeserkepova 1991; Entin et al. 2000; Seneviratne et al. 2006), and their impacts on atmospheric variability do indeed manifest themselves at those time scales, as demonstrated by various studies that quantify the impact of soil moisture initialization on the skill of subseasonal precipitation and/or temperature forecasts (e.g., Viterbo and Betts 1999; Koster et al. 2004; Douville 2010; Koster et al. 2010b; Seneviratne et al. 2010) or identified lag correlations between surface moisture deficits and temperature extremes (e.g., Hirschi et al. 2011; Mueller and Seneviratne 2012). This memory, at the same time, also allows soil moisture initialization to contribute significant skill to seasonal streamflow forecasts (e.g., Koster et al. 2010a; Mahanama et al. 2012).

The existence of this useful middle ground makes soil moisture memory worthy of careful study. A critical step in this understanding is the characterization of memory and its variations across the globe. Unfortunately, such a characterization is not straightforward. A major obstacle is the limited availability of long-term soil moisture measurements (e.g., Robock et al. 2000; Seneviratne et al. 2010; Dorigo et al. 2011). Ground measurements of soil moisture are only available at the point scale, which implies some limitation in their spatial representativeness. Although spatial variability should not be overstated (e.g., Mittelbach and Seneviratne 2012), different hydrological dynamics may be active, for example, over adjacent grassland and forest areas (Teuling et al. 2010b; Orth and Seneviratne 2012a, hereafter OS12). Also, model estimates of soil moisture cannot be used for persistence studies, given the dependence of simulated soil moisture persistence on generally unvalidated model assumptions.

In contrast, streamflow measurements are widely available, they generally cover longer periods, and they represent an integral of hydrological processes over an area. Because streamflow itself responds to soil moisture variations (see also Kirchner 2009; Mahanama et al. 2012), it is natural to ask whether streamflow measurements contain useful information on catchment-scale soil moisture anomalies and soil moisture memory. We address this question in this paper. Using an adaptation of the simple water balance model of Koster and Mahanama (2012, hereafter KM12), streamflow measurements are translated into fitted functional relationships between soil moisture and both runoff and evapotranspiration. These fitted relationships in turn provide estimates of soil moisture memory. The approach is successfully validated in three heavily monitored catchments in central Europe and is then applied to several near-natural catchments in Switzerland, providing a spatial picture of how soil moisture memory varies across the country. The analysis shows how soil moisture memory is affected by both geomorphological controls (e.g., altitude, topography, and catchment size) and meteorological controls (e.g., dryness index and the potential for externally induced memory from the atmospheric forcing to be transmitted into the soil).

\section{Methodology}

\section{a. Simple water balance model}

KM12 developed a simple water balance model to study the influence of soil moisture on hydroclimatic means and variability on large spatial and temporal scales. We use a similar approach in the present study. However, because we focus here on soil moisture memory in small catchments on daily to weekly time scales, we introduce several new features to the model, as described below.

\section{1) WATER BALANCE EQUATION}

As in KM12, the model used here is based on the following water balance equation:

$$
w_{n+\Delta t}=w_{n}+\left(P_{n}-E_{n}-Q_{n}\right) \Delta t,
$$

where $w_{n}$ denotes the model's sole prognostic variable: the total soil moisture content (in mm) at time step $n$. The value of $w_{n}$ is altered by precipitation $P_{n}$, evapotranspiration $E_{n}$, and runoff $Q_{n}$ (all in $\mathrm{mm} \mathrm{day}^{-1}$ ) accumulated from time step $n$ to $n+\Delta t$ to yield the soil moisture at the next time step, $w_{n+\Delta t}$. As in KM12, we run the model here with a time step of 1 day $(\Delta t=1$ day).

\section{2) EVAPOTRANSPIRATION}

As in KM12, we assume simple dependencies of evapotranspiration [normalized by net radiation (in $\mathrm{W} \mathrm{m}^{-2}$ )] and runoff (normalized by precipitation) on soil moisture. We use the following equation to capture the control of soil moisture on the ratio of evapotranspiration to net radiation, or ET ratio:

$\frac{\lambda \rho_{w} E_{n}}{R_{n}}=\beta_{0}\left(\frac{w_{n}}{c_{s}}\right)^{\gamma}$ with $\quad \gamma>0$ and $\beta_{0} \leq 1$,

where $\lambda$ is the latent heat of vaporization (in $\mathrm{J} \mathrm{kg}^{-1}$ ) and $\rho_{w}$ is the density of water (in $\mathrm{kg} \mathrm{m}^{-3}$ ). Soil moisture is scaled by the soil water-holding capacity $c_{s}$ (in $\mathrm{mm}$ ) so that the function operates on the degree of saturation (unitless). The unitless exponent $\gamma$ ensures that the function is strictly monotonically increasing, so that the 
ET ratio increases with soil moisture. The factor $\beta_{0}$ (also unitless) reflects the residual plant and soil evaporative resistance under conditions that are not soil moisture limited (e.g., Seneviratne et al. 2010). This factor therefore prevents the complete conversion of available net radiation into ET even when water is fully available (reflecting, for example, the fact that even with no water stress, transpiring water must still travel through the vegetation).

\section{3) RUNOFF AND STREAMFLOW}

Even if runoff in nature is controlled by many variables, we assume that it depends on precipitation and soil moisture only, according to the equation

$$
\frac{Q_{n}}{P_{n}}=\left(\frac{w_{n}}{c_{s}}\right)^{\alpha} \quad \text { with } \quad \alpha \geq 0 .
$$

As with the exponent $\gamma$ in Eq. (2), the unitless exponent $\alpha$ ensures that the runoff ratio $Q_{n} / P_{n}$ increases monotonically with soil moisture. Note that runoff as defined here (which includes, in effect, both overland flow and drainage to baseflow-producing groundwater) is distinct from streamflow, as measured at a stream gauge site; the latter quantity includes delays associated with the subsurface water transport to the streambeds and the transport of the surface water to the stream gauge site. Based on sensitivity tests, we found that accounting explicitly for this distinction between runoff and streamflow improves the model's performance in comparison to the KM12 version (not shown). We thus compute streamflow from the simulated runoff values by imposing a delay characterized by a time scale $\tau$ :

$$
S_{n+t}=Q_{n} \frac{1}{\tau} e^{-(t / \tau)},
$$

where the streamflow $S_{n+t}$ corresponds to the streamflow produced at time $n+t$ associated with the surface runoff formed at time $n$. The integral of $(1 / \tau) e^{-(t / \tau)}$ as $t \rightarrow \infty$ equals 1 , ensuring that the full complement of assumed runoff water [i.e., $P_{n}\left(w_{n} / c_{s}\right)^{\alpha}$, from Eq. (3)] does contribute to streamflow at some time. The parameter $1 / \tau$ determines how quickly the runoff is transformed into streamflow, whereas $\tau$ corresponds to the recession time scale, expressed in days. Using Eq. (4), the streamflow accumulated over the $m$ th time step after the precipitation event is

$$
\begin{aligned}
S_{n+m \Delta t} & =\left(\frac{w_{n}}{c_{s}}\right)^{\alpha} P_{n} \int_{m}^{m+\Delta t} \frac{1}{\tau} e^{-(t / \tau)} d t \\
& =Q_{n}\left[e^{-(m \Delta t / \tau)}-e^{-[(m+1) \Delta t / \tau]}\right] .
\end{aligned}
$$

With this equation we can express the streamflow at any time step as the accumulation of the effects of all runoff amounts generated during the preceding 60 time steps:

$$
S_{n}=\sum_{i=0}^{60} Q_{n-i \Delta t}\left[e^{-(i \Delta t / \tau)}-e^{-[(i+1) \Delta t / \tau]}\right]
$$

Note that in order to make sure that all the generated runoff is transformed into streamflow, we would in principle need to use an infinite number of time steps. Sixty time steps is an arbitrary but tractable number that allows us to account for $99 \%$ or more of the runoff water.

\section{4) Model InTEgRAtion}

Assuming that values for the five parameters in Eqs. (2) and (6) (namely, $c_{s}, \beta_{0}, \gamma, \alpha$, and $\tau$ ) can be determined, Eq. (1) can be driven with daily values of precipitation and net radiation over any time period of interest to produce daily time series of total soil moisture $w_{n}$, as well as daily time series of runoff and ET. In contrast to KM12, who used monthly precipitation observations (equally distributed across the days of a given month) and an observed seasonal climatology of net radiation to force their model, we employ daily observations of precipitation and radiation. Unlike KM12, we do not include a snow layer in the model as our study focuses on the growing season.

In fact, because of the limitation of using a daily (rather than a finer) time step, we integrate instead an implicit form of Eq. (1), a form that effectively computes the evaporation and runoff for a given day based on the soil moisture content at the end of that day:

$$
\begin{aligned}
w_{n+\Delta t}-w_{n} & =P_{n}-E_{n+\Delta t}-Q_{n+\Delta t} \\
& \approx \frac{P_{n}-E_{n}-Q_{n}}{1+E_{n}^{\prime}+Q_{n}^{\prime}},
\end{aligned}
$$

where the prime indicates the derivative with respect to soil moisture, evaluated at $w_{n}$. Note that even with this correction, the time-discretized equation is still not perfectly solved because the functions $E(w)$ and $Q(w)$ are not linear but (partly strongly) curved.

Running the model requires the initialization of the soil moisture prognostic variable. We spin up the model by integrating it over 5 years prior to the start of a simulation.

\section{b. Optimization of streamflow, runoff, and evapotranspiration parameters}

We optimize the above model with daily data from 16 European catchments, three of which have been previously examined in OS12. We use precipitation and 
TABLE 1. Overview of step width of model parameters as used in the optimization procedure, their boundaries, and the range of their respective estimates.

\begin{tabular}{lccccc}
\hline \hline \multicolumn{1}{c}{ Parameter } & Step width & Lower limit & Upper limit & $\begin{array}{c}\text { Maximum } \\
\text { value found }\end{array}$ & $\begin{array}{c}\text { Minimum } \\
\text { value found }\end{array}$ \\
\hline Water-holding capacity $c_{s}(\mathrm{~mm})$ & 30 & 30 & - & 500 & 80 \\
Inverse streamflow recession time scale $1 / \tau\left(\mathrm{day}^{-1}\right)$ & 0.02 & 0.02 & - & 0.80 & 0.10 \\
Runoff ratio exponent $\alpha$ & 0.2 & 0.2 & - & 8.0 & 0.8 \\
ET ratio exponent $\gamma$ & 0.03 & 0.03 & - & 1.05 & 0.03 \\
Max ET ratio $\beta_{0}$ & 0.03 & 0.03 & 0.99 & 0.99 & 0.60 \\
\hline
\end{tabular}

radiation observations in these catchments to force the model. We then identify, separately for each catchment, the optimal set of values for the five parameters in Eqs. (2) and (6), that is, the set of values that allows the modeled streamflow $S_{n}$ [Eq. (6)] to agree most closely with observed streamflow.

The accuracy of the modeled streamflow is measured with a time correlation against observed streamflow. The correlation period is limited to July through September to avoid any impact of snow, which is not included in the model (May-September for warmer site San Rossore). The absence of snow is supported by daily average temperatures that are always above $0^{\circ} \mathrm{C}$ during the correlation period. Note that while applied here to specific basins in Switzerland, the simple water balance model is generally applicable to any region and time period where streamflow is present.

One way to find the optimal set of values for the five parameters at each catchment would be to run the model using all possible combinations of values. Capturing the optimal values in this way with some accuracy, however, would be computationally prohibitive. To work around this problem, we developed an alternative procedure (see the appendix) to reduce the number of model runs required to yield a reliable optimal parameter set (see Table 1).

\section{c. Validation of approach: Soil moisture memory}

The time series of simulated soil moisture produced with the optimal parameters, a reflection of precipitation, radiation, and streamflow information only, is compared to the observed soil moisture in three highly monitored catchments to demonstrate that the precipitation, radiation, and streamflow data can indeed be translated into useful information on local soil moisture behavior. Because observed soil moisture information was not used at all in the calibration exercise, this comparison serves as a valid test of our methodology.

The validation focuses in particular on soil moisture persistence. There are many ways of quantifying soil moisture persistence; here, we compute it, for a given time of the year, as a lag correlation for a given lead (see
Koster and Suarez 2001; Seneviratne and Koster 2012; OS12) that ranges between 0 (no memory) and 1 (maximum memory). The memory we compute at a given day with a given time lag is defined as

$$
\rho\left(w_{n}, w_{n+t_{\text {lag }}}\right)=\frac{\operatorname{cov}\left(w_{n}, w_{n+t_{\text {lag }}}\right)}{\sigma_{w_{n}} \sigma_{w_{n+t_{\text {lag }}}}},
$$

where $\operatorname{cov}\left(w_{n}, w_{n+t_{\text {lag }}}\right)$ denotes the covariance between soil moisture at days $n$ and $n+t_{\text {lag }}$ in all considered years and $\sigma_{w_{n}}$ refers to the standard deviation of soil moisture at day $n$ using also the values of all considered years. Because of the limited available number of years of soil moisture observations (see section 3a), we in fact do some smoothing of the calculated persistences, computing representative estimates for half-monthly intervals. To determine the smoothed persistence for a given halfmonthly interval, we use a "moving window" approach (OS12) that also considers the 30 days prior to the halfmonthly interval and the 30 days after the end of the half-monthly interval. This can be expressed mathematically as

$$
\begin{aligned}
& \rho\left(w_{n}, w_{n+t_{\text {lag }}}\right) \\
& \quad=\text { trimmed average }\left[\sum_{i=t_{\text {start }}-30}^{t_{\text {end }}+30-t_{\text {lag }}} \rho\left(w_{i}, w_{i+t_{\text {lag }}}\right)\right],
\end{aligned}
$$

where $t_{\text {start }}$ and $t_{\text {end }}$ refer to the beginning and end of the particular half-monthly time period. The memory of that half-monthly interval is then computed as a trimmed average of the $75 t_{\mathrm{lag}}$ individual persistences, avoiding days with the $10 \%$ largest and $10 \%$ lowest values (this last step differs from the approach of OS12, who take the median).

We compute the correlation for many different lags (from 1 to 40 days) in order to capture more completely the character of the persistence. One region may show high correlations at small lags and a rapid falloff in correlation at longer lags, and another may show a fast falloff at short lags and a slower falloff thereafter; our 
TABLE 2. Overview of measurements and conditions at the sites and catchments used for validating the model as well as references describing the sites in more detail. $\mathrm{CH}$ is Switzerland, ITA is Italy.

\begin{tabular}{|c|c|c|c|c|}
\hline Station & Data period & Land cover & Soil type & SM measurement depths $(\mathrm{m})$ \\
\hline Oensingen $(\mathrm{CH})$ & $2002-07$ & Grassland & Clay & $0.05,0.1,0.3,0.5$ \\
\hline Rietholzbach $(\mathrm{CH})$ & 1994-2007 & Grassland & (Clay) loam & $0.05,0.15,0.55$ \\
\hline San Rossore (ITA) & $2004-10$ & Forest & Sand & $0.1,0.3,0.45$ \\
\hline
\end{tabular}

\begin{tabular}{llccc} 
& $\begin{array}{c}\text { Streamflow station } \\
\text { (distance and direction } \\
\text { Station }\end{array}$ & Catchment area & $\begin{array}{c}\text { Satellite radiation } \\
\text { coordinates }\end{array}$ & Reference \\
\hline Oensingen $(\mathrm{CH})$ & Brugg $(38 \mathrm{~km}$ east) & $11726 \mathrm{~km}^{2}$ & $47.5^{\circ} \mathrm{N}, 7^{\circ} \mathrm{E}$ & Ammann et al. (2010) \\
Rietholzbach $(\mathrm{CH})$ & Mosnang $(1.5 \mathrm{~km})$ & $3.3 \mathrm{~km}^{2}$ & $47.5^{\circ} \mathrm{N}, 9^{\circ} \mathrm{E}$ & $\begin{array}{l}\text { Seneviratne et al. (2012) } \\
\text { San Rossore (ITA) }\end{array}$ \\
\hline
\end{tabular}

computations will capture such differences in behavior. Thus, we calculate, from both observations and the simulations with optimized parameters, the correlation between soil moisture on a given date $n$ with that at a later date $\left(n+t_{\mathrm{lag}}\right)$ across all years [Eq. (9)]. By computing a separate correlation for each date across all years, we avoid examining artificial memory associated with the climatological seasonal cycle of soil moisture. The higher the resulting correlation over a prescribed lag time, the higher we deem the soil moisture memory at that lag, and vice versa. Soil moisture memory is always decreasing with increasing time lag because accumulated precipitation, runoff, and ET alter the soil moisture content [Eq. (1)]. To facilitate the interpretation of soil moisture memory expressed as lag correlation, Orth and Seneviratne (2012b) compared the lag correlation with a persistence time scale (computed as mean duration to recover from anomalous conditions exceeding a certain threshold to normal conditions, expressed in days). They report an exponential relationship, that is, the persistence time scale changes exponentially with linearly changing lag correlation.

Similarly to Eq. (9), but without time lag, we compute estimates for the standard deviations of, for example, initial soil moisture over all estimates of day $n$ of all years. Using the moving window approach, we obtain a number of estimates from which we take a trimmed average as a representative estimate for a particular half-monthly interval.

Soil moisture persistences in this study are computed from April to October to exclude the impact of snow cover, which is not included in the model. We therefore apply the model in an extended period compared to the period July-September used for optimization to allow us to show that the model also performs reasonably in months that are not used for calibration, but that are still mostly snow-free (underlined by daily average temperatures above $0^{\circ} \mathrm{C}$ on almost all days).
To compute uncertainties of the soil moisture memory estimates, we separate the whole time period (24 years; see section $3 \mathrm{~b}$ ) into nonintersecting subsets of 3 years (period July-September in each year as described in section $2 \mathrm{~b}$ ) and optimize the model in each catchment to yield one parameter set per subset for a particular catchment. This is done with five repetitions for each subset (instead of 20 used for the whole time series) because of computational constraints. We apply all parameter sets of a particular catchment with the whole time series and derive respective soil moisture memories; from these memories we then compute the standard deviations for every considered month and lag time.

\section{Data}

\section{a. Data analyzed for model validation}

To validate the model, we use data from the three heavily monitored catchments: Oensingen (Switzerland), Rietholzbach (Switzerland), and San Rossore (Italy). The climate at the Swiss sites is temperate humid, whereas San Rossore is characterized by Mediterranean climate. Along with the stream gauge measurements for the full catchments, there is a site in each catchment where ET, radiation, and precipitation have been recorded. Detailed information on the catchments and sites is provided in Table 2.

ET at Rietholzbach was measured using a weighing lysimeter (Seneviratne et al. 2012), whereas the eddy covariance flux measurement method (Baldocchi et al. 2001) was used at the other two sites. As this latter method is known for its energy balance closure error (e.g., Wilson et al. 2002; Foken et al. 2006; Franssen et al. 2010), we corrected the ET data with the following procedure: using hourly values, we increased sensible and latent heat flux to equal net radiation while keeping the Bowen ratio constant (Twine et al. 2000). If the Bowen ratio was negative, both fluxes were adjusted with respect 
to the strength of their dependence on net radiation instead. This strength was the slope obtained from the regression of all available values of the particular flux against net radiation on a particular time of the day; the flux with the higher slope was modified by the larger fraction of the energy balance deficit. Note that the ET data from San Rossore could not be corrected as no data of sensible heat flux is available for that site. Furthermore, we linearly detrended the soil moisture data from Rietholzbach to address a known problem with the sensors there (see also Seneviratne et al. 2012).

At all three catchments, we use satellite-derived net radiation data obtained from the National Aeronautics and Space Administration (NASA)/Global Energy and Water Cycle Experiment (GEWEX) surface radiation budget (SRB) project (http://gewex-srb.larc.nasa.gov/ common/php/SRB_data_products.php). Since these data only extend until 2007, we had to extrapolate net radiation from the available solar radiation measurements for the remaining 3 years at San Rossore. These were scaled to match the mean and standard deviation of the satellite net radiation of the previous 4 years. To evaluate the impact of this treatment we also applied such a scaling to solar radiation measured at Oensingen and found only minor impacts on the results there, predominantly on ET (not shown).

\section{b. Data used for model application}

Following validation, we apply the model to 13 nearnatural catchments (i.e., catchments with little or no known human impact on streamflow) across Switzerland for which detailed stream gauge data are available. The catchments are located in a humid temperate climate, except for the Cassarate catchment in southern Switzerland, where the climate is rather Mediterranean. A summary of the catchment characteristics is provided in Table 3. The time period considered is 1984-2007.

For this period, we also obtained catchment-specific precipitation and radiation data. Precipitation forcing for the model was derived from several MeteoSwiss (Swiss Federal Office of Meteorology and Climatology) rain gauges in and/or near each respective catchment. The number of rain gauges per catchment depends on the size of the respective catchment and on the density of the network in the particular region (see http://www.meteoschweiz.admin.ch/web/de/ klima/messsysteme/boden.Par.0049.DownloadFile.tmp/ karteniederschlagsmessnetz.pdf). The measurements were weighted inversely according to their distance from the catchment in order to compute an area-representative estimate. As only solar radiation was measured at the ground, we used net radiation data from the NASA/ GEWEX SRB project. A comparison of anomalies of
TABLE 3. Overview of catchments where the model is applied.

\begin{tabular}{lrrrcc}
\hline \hline Catchment & $\begin{array}{c}\text { Size } \\
\left(\mathrm{km}^{2}\right)\end{array}$ & $\begin{array}{c}\text { Mean } \\
\text { altitude } \\
(\mathrm{m} \mathrm{MSL})\end{array}$ & $\begin{array}{c}\text { Mean } \\
\text { CTI }\end{array}$ & $\begin{array}{c}\text { Mean daily } \\
\text { streamflow } \\
(\mathrm{mm})\end{array}$ & $\begin{array}{c}\text { Satellite } \\
\text { radiation } \\
\text { coordinates }\end{array}$ \\
\hline Aach & 49 & 480 & 11.82 & 1.32 & $47.5^{\circ} \mathrm{N}, 9^{\circ} \mathrm{E}$ \\
Broye & 392 & 710 & 11.33 & 1.78 & $46.5^{\circ} \mathrm{N}, 7^{\circ} \mathrm{E}$ \\
Cassarate & 74 & 990 & 9.39 & 2.72 & $45.5^{\circ} \mathrm{N}, 9^{\circ} \mathrm{E}$ \\
Emme & 124 & 1189 & 10.03 & 3.01 & $46.5^{\circ} \mathrm{N}, 7^{\circ} \mathrm{E}$ \\
Ergolz & 261 & 590 & 10.99 & 1.25 & $47.5^{\circ} \mathrm{N}, 7^{\circ} \mathrm{E}$ \\
Goldach & 50 & 833 & 10.71 & 2.32 & $47.5^{\circ} \mathrm{N}, 9^{\circ} \mathrm{E}$ \\
Guerbe & 54 & 837 & 9.98 & 2.01 & $46.5^{\circ} \mathrm{N}, 7^{\circ} \mathrm{E}$ \\
Kleine Emme & 477 & 1050 & 10.48 & 2.81 & $46.5^{\circ} \mathrm{N}, 7^{\circ} \mathrm{E}$ \\
Langeten & 60 & 766 & 11.37 & 1.79 & $47.5^{\circ} \mathrm{N}, 7^{\circ} \mathrm{E}$ \\
Mentue & 105 & 679 & 11.27 & 1.34 & $46.5^{\circ} \mathrm{N}, 7^{\circ} \mathrm{E}$ \\
Murg & 79 & 650 & 11.47 & 1.98 & $47.5^{\circ} \mathrm{N}, 9^{\circ} \mathrm{E}$ \\
Sense & 352 & 1068 & 10.5 & 2.18 & $46.5^{\circ} \mathrm{N}, 7^{\circ} \mathrm{E}$ \\
Sitter & 74 & 1252 & 10.18 & 4.06 & $47.5^{\circ} \mathrm{N}, 9^{\circ} \mathrm{E}$ \\
\hline
\end{tabular}

the solar radiation measured at the ground with that from SRB showed correlations between 0.8 and 0.9 for the different catchments, underlining the good match also reported by OS12.

To study the dependency of soil moisture memory on topography (hilliness), we obtained values of mean compound topographic index (CTI; Moore et al. 1993) from the HYDRO-1K dataset (http://webgis.wr.usgs. gov/globalgis/metadata_qr/metadata/hydro1k.htm). As a measure of topography for each catchment, the CTI is a function of slope as well as upstream contributing area and increases with decreasing hilliness. Note that CTI is only evaluated at the catchments used for application of the model and not at the three validation catchments that include the very small Rietholzbach catchment. Therefore, the $1 \mathrm{~km} \times 1 \mathrm{~km}$ resolution is sufficient to characterize, to first order, the CTI among the catchments examined.

\section{Results}

In this section we first describe the application and validation of the simple model methodology in three heavily monitored catchments (sections $4 b$ and $4 c$ ). We show its satisfactory ability to yield a realistic soil moisture memory despite its simplicity. In section $4 \mathrm{~d}$ we describe the application of the model in multiple catchments across Switzerland. This allows us to study the main meteorological controls of soil moisture memory as well as its dependency on altitude and topography.

\section{a. Streamflow, runoff, and evapotranspiration parameters}

To summarize our methodology, we optimize the applied simple water balance model (i.e., we find optimized values for its five parameters) so that it reproduces well 
TABLE 4. Overview of fitted parameters for all catchments.

\begin{tabular}{|c|c|c|c|c|c|}
\hline Catchment & $\begin{array}{l}\text { Water-holding } \\
\text { capacity } c_{s}(\mathrm{~mm})\end{array}$ & $\begin{array}{l}\text { Inverse streamflow recession } \\
\text { time scale } 1 / \tau\left(\text { day }^{-1}\right)\end{array}$ & Runoff ratio exponent $\alpha$ & ET ratio exponent $\gamma$ & Max ET ratio $\beta_{0}$ \\
\hline \multicolumn{6}{|c|}{ Catchments in which model is validated } \\
\hline Oensingen & 410 & 0.10 & 0.8 & 0.03 & 0.60 \\
\hline Rietholzbach & 140 & 0.80 & 4.4 & 0.42 & 0.99 \\
\hline San Rossore & 500 & 0.14 & 3.6 & 0.03 & 0.96 \\
\hline \multicolumn{6}{|c|}{ Catchments in which model is applied } \\
\hline Aach & 230 & 0.62 & 8.0 & 0.78 & 0.99 \\
\hline Broye & 200 & 0.36 & 5.8 & 0.42 & 0.60 \\
\hline Cassarate & 410 & 0.36 & 6.8 & 0.33 & 0.81 \\
\hline Emme & 80 & 0.74 & 1.4 & 0.27 & 0.99 \\
\hline Ergolz & 290 & 0.54 & 5.6 & 0.90 & 0.99 \\
\hline Goldach & 350 & 0.60 & 6.8 & 0.75 & 0.99 \\
\hline Guerbe & 170 & 0.44 & 4.2 & 1.05 & 0.99 \\
\hline Kleine Emme & 80 & 0.66 & 2.4 & 0.60 & 0.99 \\
\hline Langeten & 320 & 0.52 & 4.0 & 0.06 & 0.81 \\
\hline Mentue & 410 & 0.52 & 6.4 & 0.66 & 0.99 \\
\hline Murg & 230 & 0.50 & 6.2 & 0.63 & 0.99 \\
\hline Sense & 80 & 0.52 & 1.6 & 0.09 & 0.69 \\
\hline Sitter & 170 & 0.56 & 7.4 & 0.90 & 0.69 \\
\hline
\end{tabular}

the time variations in the daily streamflows measured in a given catchment when forced with local precipitation and net radiation data. An overview of the fitted parameters in all catchments is provided in Table 4.

A note about the parameter search is appropriate here. Two parameters, the ET ratio exponent and maximum ET ratio, collide with their bounds in two and nine catchments, respectively, out of the 16 catchments considered in total in this study (see Table 1 for bounds and Table 4 for fitted parameters). Concerning the maximum ET ratio, the fact that the optimum value of $\beta_{0}$ is found to be exactly 1 , an imposed bound for the parameter, does not reflect poorly on the parameter estimation approach; the optimized value of 1 simply means that for the catchment in question, all of the net radiation is converted to evaporation in wet conditions, a physically plausible scenario. Our requirement that $\beta_{0}$ cannot exceed 1 is simply a reflection of our assumption that net radiation provides the energy needed for evaporation. Whereas high maximum ET ratios are not surprising in a radiation-limited regime that is characteristic for Switzerland, we note the possibility that in nature, ET might (temporarily) exceed net radiation through processes that are not captured by our simple model, such as energy input from warm air advection to Europe; therefore, the collisions experienced with the $\beta_{0}$ term can be said to reflect the limitations of our assumption. Note that both parameters that collide with their bounds are related to radiation [Eq. (2)] and streamflow (through optimization procedure, see section $2 b$ ). Therefore, it is furthermore possible that these collisions are due to scale discrepancies between radiation and streamflow measurements and the consequent mismatch in their temporal evolutions. However, the parameter collisions should, in any case, not have a major impact on the resulting estimated soil moisture memory as indicated by supplemental tests (not shown) in which the bounds were removed (in conflict with the model's underlying assumptions) and the results were found to be generally similar. Furthermore, we note that, despite the parameter collisions, we find a good match between modeled and observed soil moisture memory as described in the following subsection.

To validate our optimization procedure, we applied it with higher (coarser) step widths for the parameters and then compared the results with those obtained when all possible combinations of parameters (assuming the same coarse spacing) were tested. This allowed us to compare the resulting best parameter sets. Given the high computational effort, the validation was done only for the three catchments listed in Table 2. The best parameter sets found from both procedures were identical for all three catchments (see Table 4 for parameter values), underlining the validity of the approach introduced in this study. As expected because of the larger step width (lower accuracy), these parameter sets yield slightly lower correlations between observed and modeled streamflow compared to the parameter sets found using the default step widths (see Table 1).

\section{b. Validation of estimated memory}

In addition to generating realistic streamflows, the optimized model produces, as a matter of course, a time series of daily soil moisture, from which soil moisture 


\section{Oensingen}

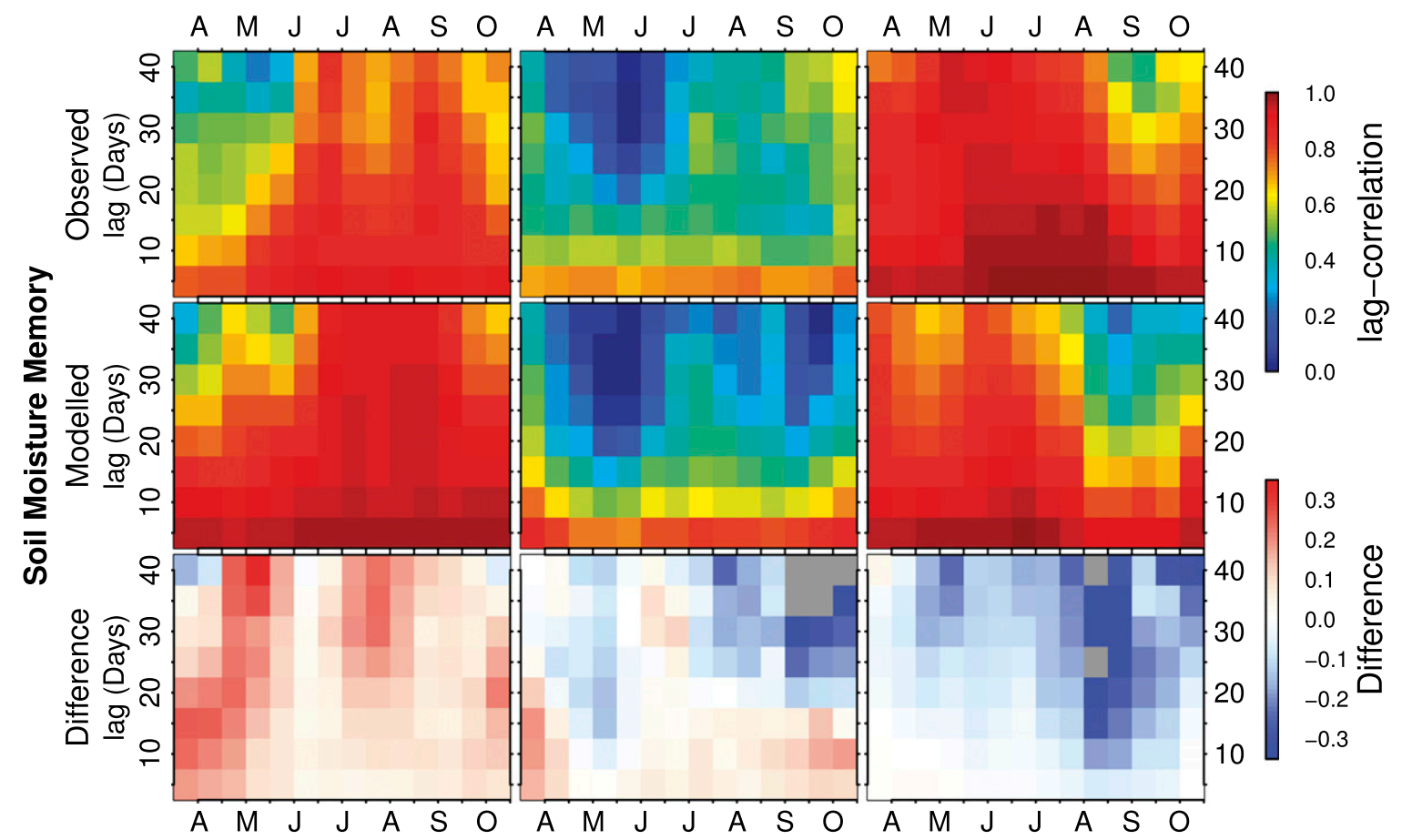

FIG. 1. Soil moisture memory computed from observed and modeled soil moisture in the three validation catchments for lag times between 5 and 40 days. Values outside the plotting range of the difference plots are shaded in gray.

persistence measures can be derived. Our methodology for converting streamflow measurements into soil moisture information is deemed successful if the derived soil moisture persistences obtained from this time series agree with those obtained using independent soil moisture measurements in the catchments.

This validation test was performed in each of the three catchments described in section 3a. Results are shown in Fig. 1. Shown for each catchment are the modeled and observed persistences for different lags (out to 40 days) and for different times of the year (April-October). Overall, the memory characteristics in the three catchments are well captured by the model, with a reasonable representation in each of the seasonal cycle of soil moisture memory and its decay with lag. The observed and simulated memory is comparatively strong at Oensingen and San Rossore and weakest at Rietholzbach. The seasonal cycle of the observed memory at San Rossore differs clearly from that of the other two sites, and this is captured by the model. Difference plots are shown in the bottom row of the figure; there is no clear pattern of overand underestimation of memory in the simulation results. The relatively large difference between modeled and observed soil moisture memory in autumn at both Rietholzbach and San Rossore is consistent with results of OS12 (their Fig. 6), who used the same atmospheric forcing data and also derived a clearly underestimated soil moisture memory. In this previous study, the identified reason for this behavior was a mismatch between precipitation and soil moisture observations in autumn at these two sites. This means that the water balance is not closed with the employed observations, which could be due, for example, to a higher spatial variability of precipitation or a stronger role of land cover in this season.

The model, using only information on locally measured precipitation, net radiation, and streamflow, therefore successfully captures the distinctions between the catchments in their soil moisture memory behavior. Despite its simplicity, it captures enough of the physical processes controlling memory to allow the translation of streamflow information into soil moisture information. Furthermore, the agreement in Fig. 1 suggests (as does the reasonable reproduction of soil moisture anomalies shown below) that the time behavior of the observed site-based soil moisture anomalies is representative of that for soil moisture across the catchment containing the site; that is, soil moisture levels may be spatially heterogeneous within a catchment but may nevertheless show similar temporal dynamics. This is consistent with results from Mittelbach and Seneviratne (2012) for Switzerland based on measurements from the Swiss Soil Moisture 
Experiment (SwissSMEX), which show that soil moisture dynamics have a large regional footprint in that region, unlike absolute soil moisture that displays a stronger spatial variability.

To illustrate further the impact of the fitted parameter set on the resulting soil moisture memory characteristicsin particular, to show the relative impacts on memory of the parameter values and the meteorological forcing-we run the model at each of the three sites mentioned above with the parameter set fitted for the particular site and also with the parameter sets fitted for the other two sites. The results are displayed in Fig. 2. We find that the parameter set is more important for determining the resulting soil moisture memory than is the meteorological forcing. There are similarities between the actual modeled memory at Oensingen and San Rossore and the resulting memory when using the parameter set or meteorological forcing from another site. This can be explained by the roughly similar fitted parameters (see Table 4). Generally, the strong sensitivity of the memory with respect to the parameter set underlines the ability of our simple model framework to yield a parameter set that is related with realistic features of the studied catchments.

\section{c. Hydrological states and fluxes}

While the main goal of the tested methodology is the extraction of soil moisture memory statistics, we can also validate the soil moisture, streamflow, and evapotranspiration time series produced by the optimized model against available observations in the three validation catchments. Comparisons of the observed and simulated anomalies of these quantities are provided in the top three rows of Fig. 3. Mean seasonal cycles have been subtracted from both the observed and simulated data in order to avoid an overestimation of model skill associated with the seasonal cycles inherent in the precipitation and net radiation forcing. While this subtraction also prevents a proper evaluation of bias, such bias evaluations would, in any case, be of limited usefulness: (i) significant biases are likely in the observed evaporation data given the closure problem associated with eddy covariance measurements (see section 3a); (ii) biases in soil moisture are likely because the model uses an arbitrary wilting point (which does not affect the temporal variability of the soil moisture it produces); (iii) observed absolute soil moisture is also expected to vary strongly even on small spatial scales, and only the temporal dynamics should display a regional footprint (Mittelbach and Seneviratne 2012); and (iv) biases in streamflow may occur especially in flat catchments through baseflow out of the catchment away from the stream gauge.
Overall, the model seems to do especially well in estimating soil moisture variations, particularly for Oensingen $\left(R^{2}=0.78\right)$ but also for Rietholzbach $\left(R^{2}=\right.$ $0.62)$. Streamflows for these two sites are also reasonably reproduced ( $R^{2}$ values of 0.6 and 0.87 , respectively), whereas simulated ET values are somewhat less consistent with the observations, although still satisfactory at Rietholzbach $\left(R^{2}=0.58\right)$. The simulated values are always worse for the San Rossore catchment, possibly because of (i) its larger size and the corresponding reduction in the large-scale representativeness of its site-based precipitation forcing and (ii) the interpolation of the radiative forcing (see lower part of section 3a). In cases of comparatively low $R^{2}$ values, such as for ET at Oensingen and for all quantities at San Rossore, we find that the model tends to underestimate the variability of the anomalies, as indicated by the regression slopes that are clearly smaller than 1 .

Corresponding scatterplots produced with data from June and October (not shown) show comparable agreement between the model results and observations. This provides an independent evaluation of model performance, given that these months were not part of the fitting period (see section $2 b$ ).

The bottom row in Fig. 3 displays the optimized runoff functions (solid red lines) and ET functions (solid black lines) at Oensingen, Rietholzbach, and San Rossore. Every plotted point represents either an observed streamflow ratio, $S_{n} / P_{n}$ (in red), or an observed ET ratio, $\lambda \rho_{w} E_{n} / R_{n}$ (in black), with the respective quantities (both the numerators and the denominators separately) accumulated over a week to increase representativeness and to ensure comparability between runoff ratio as shown by the fitted function and streamflow ratio in the observations.

At first glance, the evaporation functions seem to disagree with the data. Here one must remember two key points: (i) no evaporation data were used in the optimization of the functions and (ii) the evaporation observations are subject to bias and, even after bias correction, are uncertain. Eddy covariance measurements are known, for example, to produce underestimated fluxes (e.g., Wilson et al. 2002; Foken et al. 2006; Franssen et al. 2010). Therefore, we corrected the ET in order to close the energy balance through a modification of latent and sensible heat fluxes, as described in section $3 \mathrm{a}$. Indeed, at Rietholzbach, where ET was measured with a weighing lysimeter instead, the modeled ET ratio compares better to observations. At San Rossore, the ET data could not be corrected because net radiation was not available over the whole time period; the observed ET fluxes there are thus underestimated. (Such errors might also explain the relatively poor comparison of ET 


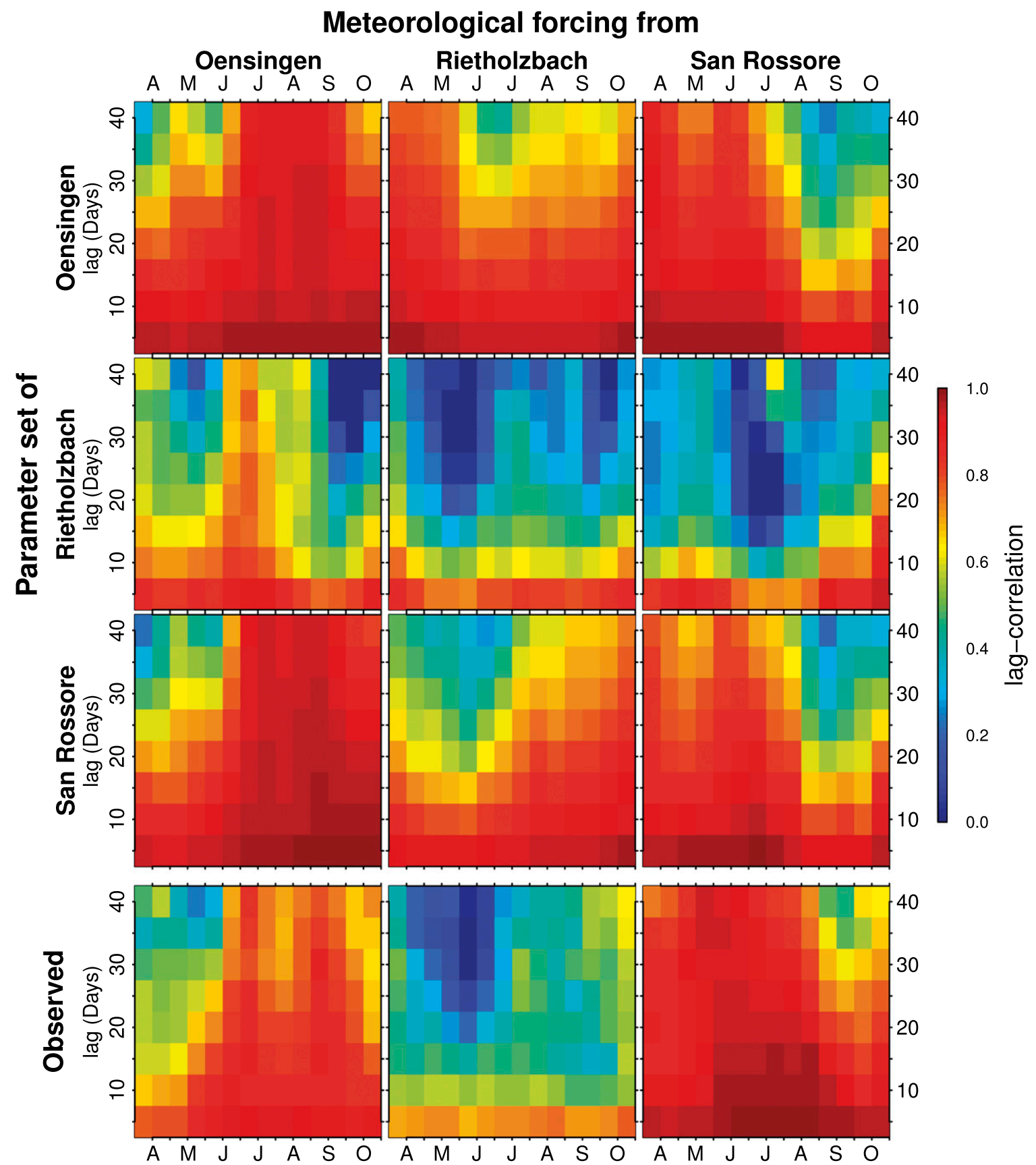

FIG. 2. Soil moisture memory computed for all possible combinations of meteorological forcings and parameter sets from the three validation catchments as compared to observed soil moisture memory displayed in the bottom row.

anomalies at San Rossore in the third row of Fig. 3). At Oensingen, ET flux corrections may have led to excessive ratios, possibly because ET was measured over grassland, whereas the optimized function represents the whole catchment, which includes forested regions. Teuling et al. (2010b, their Fig. 1), using observations, showed that forests in temperate Europe use water more conservatively than grassland, especially under extreme conditions.
In contrast, the optimized runoff functions do capture, to first order, the observed streamflow ratios. This makes sense, given that the streamflow measurements were used in the optimization procedure. The high fitted runoff ratio (especially for wet conditions) corresponds well with the generally wet regime at Rietholzbach (annual precipitation $\approx 1500 \mathrm{~mm}$ ), such that most of the precipitation cannot be stored but runs off instead. There 

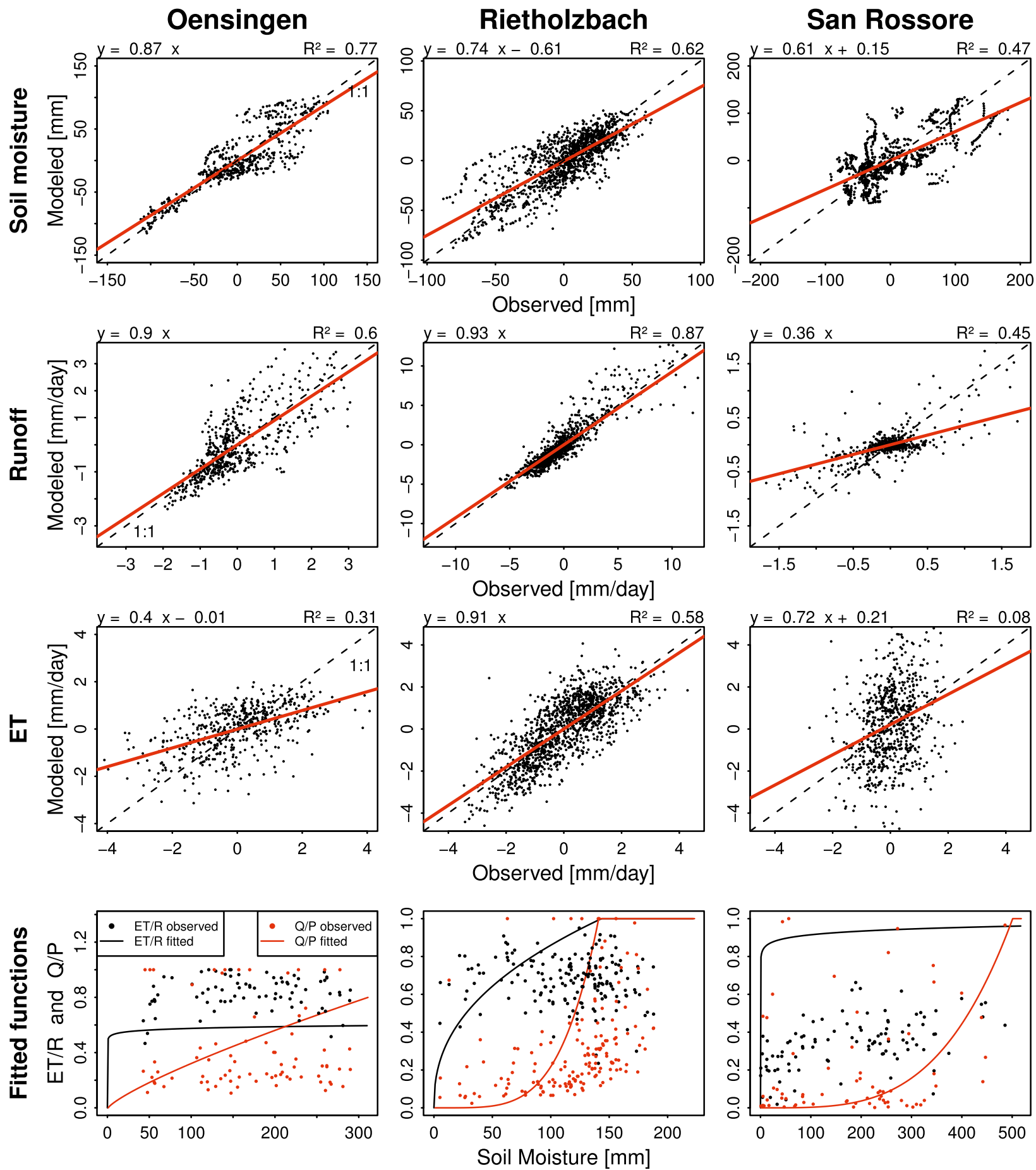

FIG. 3. Modeled (top row) soil moisture, (second row) streamflow, and (third row) evapotranspiration plotted against observations for data within the period July-September that was used to fit the functions. The red lines are fitted through least squares regressions. (bottom row) The functions of Eqs. (2) (black) and (6) (red) fitted for each catchment. These are compared to weekly averaged observed corresponding ratios plotted as points against observed soil moisture (mean and variance adapted to model soil moisture). 


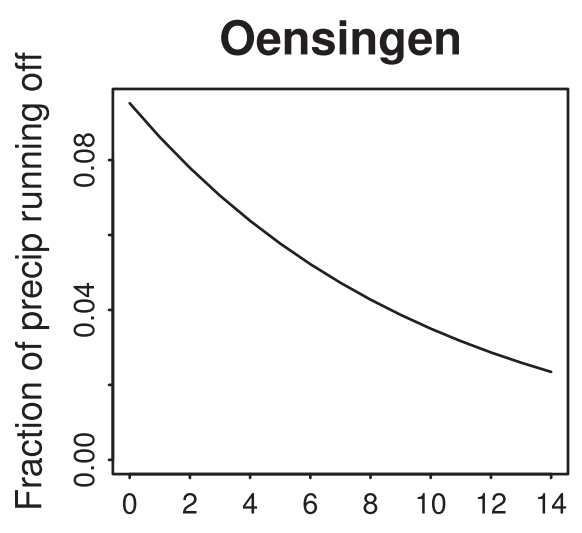

Rietholzbach

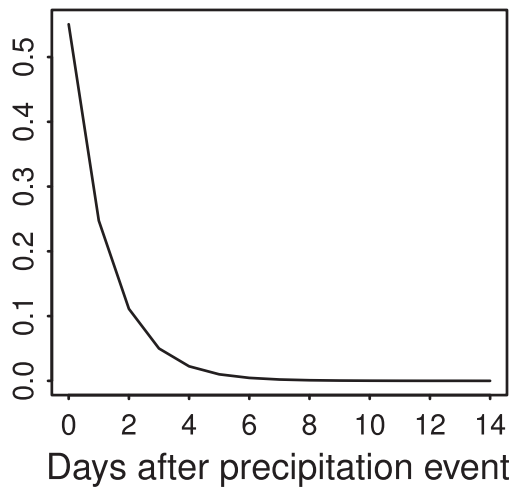

San Rossore

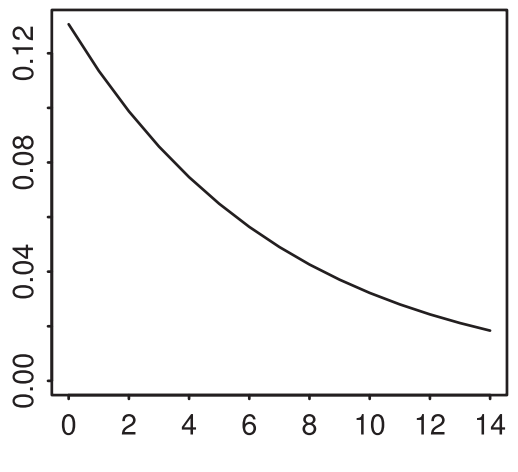

FIG. 4. Fitted hydrographs [Eq. (4)] in the three validation catchments.

is nevertheless still some bias seen in the optimal runoff functions and a substantial amount of scatter seen in the streamflow ratio observations. Again, our use of available streamflow and precipitation observations is made difficult by the mismatch in their scales; because the functions are optimized using data from July to September, we speculate that local thunderstorms and showers might influence parts of a catchment not captured by the rain gauge or might overemphasize small-scale storms falling over the rain gauges. Of course, even without a scale mismatch, scatter in the plotted points will result from the fact that precipitation and streamflow measurements each have their own errors, and these errors are compounded when the ratio is computed. Again, some time shift between precipitation and streamflow is already implicitly included in Eqs. (4)-(6) through the streamflow recession.

Summing up, we note that, generally, the unimpressive agreement found in the bottom row in Fig. 3 is no surprise given the vastly different scales we consider (e.g., for streamflow and precipitation or of modeled, catchment-scale ET and observed, point-scale ET) and the noted measurement uncertainties related to, for example, eddy covariance ET measurements or pointscale precipitation measurements. When considering this unimpressive agreement, it is worth remembering that the optimization procedure focuses on finding the runoff and evaporation functions that best reproduce the time variability of the observed streamflow (through an $R^{2}$ value), a reflection of the time dynamics of the local hydrological cycle, rather than functions that are necessarily consistent with direct evaporation and streamflow measurements, as represented by the plotted points in the lowest row of Fig. 3. Naturally, if the latter approach were used, the functions chosen would agree much more strongly with those plotted points. Of course, the latter approach requires soil moisture and evaporation information, which is what we want to avoid here, given the noted dearth of contemporaneous soil moisture and evaporation data. While it is certainly possible that our optimization approach does not produce the runoff function and ET function combination that best reproduces the measured soil moisture memory, it does nevertheless produce a combination that reproduces it reasonably well (Fig. 1), and it does maintain the critical advantage of being based on only streamflow, precipitation, and radiation information.

Note furthermore that the suitability of the optimization approach may vary depending on the climate regime, as it becomes difficult, under dry conditions when streamflow variations are small, to infer hydrological variability of a catchment from streamflow only (e.g., Teuling et al. 2010a).

For completeness, Fig. 4 shows the hydrographs associated with the optimized values of $\tau$ for the three catchments. In the Rietholzbach catchment, the streamflow response falls off most quickly, as might be expected given the catchment's hilliness and relatively small size. In the other two catchments, $2 \%$ of the water in a precipitation event is still running off 2 weeks after the event.

\section{d. Application to multiple Swiss catchments}

The application of the methodology to precipitation, net radiation, and streamflow data in 13 catchments across Switzerland (section 3b) allows us to obtain an areal picture of soil moisture memory (30-day-lagged autocorrelation), as shown in Fig. 5. The similar memories found for adjacent catchments, even those with different sizes, provide additional support for our approach. A signature of the alpine ridge (and its associated precipitation regime) is seen in the memory distribution.

The highest memory is found for the Langeten catchment, which is located in the Swiss plateau between the Alps and the Jura Mountains. High memory is also found 


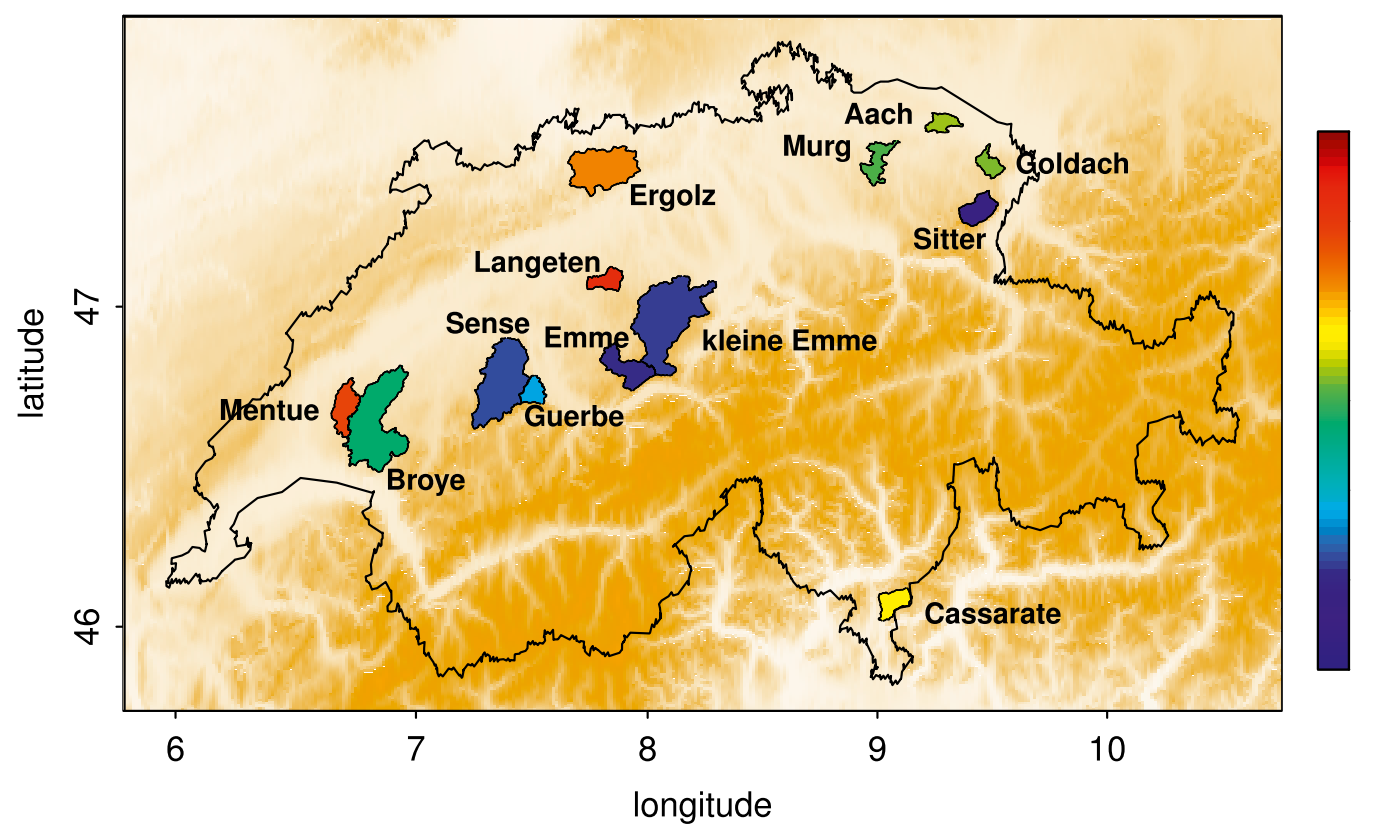

\section{6}

0.5

FIG. 5. Soil moisture memory of lag 30 days at all investigated catchments across Switzerland, averaged from April through October. The brownish background indicates the topography, with darker brown referring to higher elevations.

for the Mentue (also in the Swiss plateau) and Ergolz (northern end of the Jura Mountains) catchments. The lowest memory is found in the highest catchments: Sitter, kleine Emme, Emme, and Sense. Overall, soil moisture memory seems to increase with increasing distance from the Alps, as seen in the far west for the Broye and Mentue catchments and in the far east for the Murg, Aach, Goldach, and Sitter catchments. Despite the drier climate regime south of the Alps, we find a similar strength of the soil moisture memory at Cassarate compared to catchments along the northern alpine front.

Figure 6 summarizes the results for all catchments, showing the optimized runoff and ET functions (first column) and the corresponding soil moisture memories as a function of season and lag (second column). The rows holding the catchment results are arranged in order of average memory, starting with Langeten (the catchment with the strongest memory). The optimized functions differ significantly among the catchments, as does the absolute soil moisture range. Correspondingly, the strength of the estimated soil moisture memory and its seasonal cycle differ significantly across the catchments, especially in summer. In general, memory seems to be strongest in autumn, for which considerable memory is often seen at 4-5week lags, and it is weakest in spring, which generally shows almost no significant memory beyond 2 weeks.

Figure 6 also displays the uncertainties corresponding to the soil moisture memories, as derived with the methodology described in section $2 \mathrm{c}$. They are mostly smaller than 0.2 , indicating that the computed memory patterns are robust with respect to parameter sets obtained from different and independent subsets of the full time period analyzed. Especially if the estimated memory is high, the uncertainties are low; therefore, high soil moisture memory as identified with the simple water balance model is particularly reliable.

\section{1) CONTROLS OF SOIL MOISTURE MEMORY IN SWITZERLAND}

OS12 identified two main controls of soil moisture memory at five sites in central and Mediterranean Europe: (i) the ratio between the variability of initial soil moisture and subsequent forcing and (ii) the correlation between initial soil moisture and the subsequent forcing. They also report that the forcing is dominated by precipitation, and thus, we can express the first control as the unitless ratio between the standard deviation of initial soil moisture and the standard deviation of subsequent precipitation:

$$
\tilde{\kappa}_{n}=\frac{\sigma_{w_{n, y}}}{\sigma_{P_{n, y} t_{\text {lag }}}},
$$

where $P_{n, y}$ denotes precipitation (in $\mathrm{mm} \mathrm{day}^{-1}$ ) between date $n$ and $n+t_{\text {lag }}$ of year $y$. It is multiplied with $t_{\text {lag }}$ to yield the accumulated precipitation during that interval. The standard deviations are computed as described in section 2c. Note that $\tilde{\kappa}_{n}$ also reflects the impact of seasonal variations in precipitation. Given that precipitation dominates the forcing, the second control identified in 


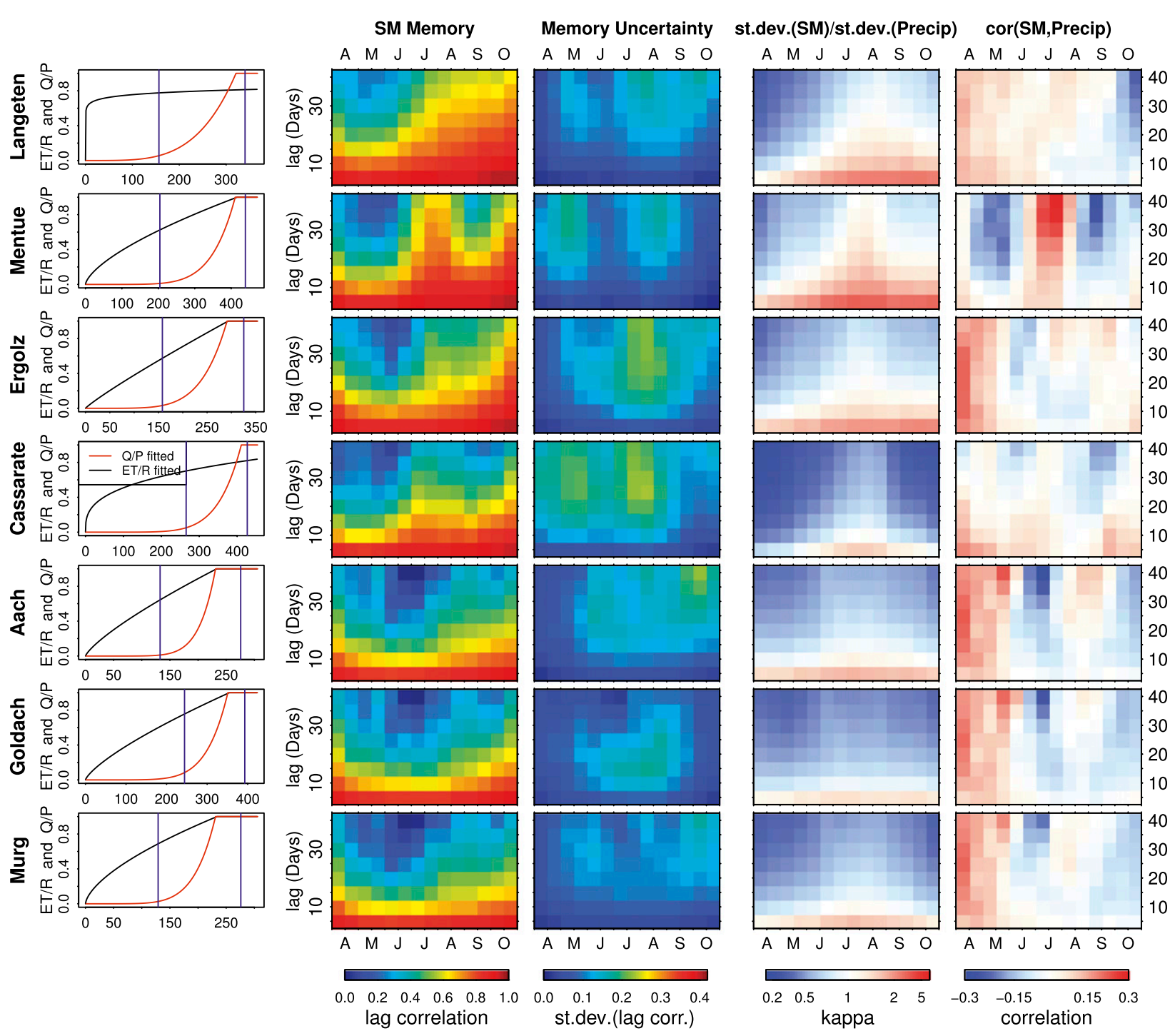

FIG. 6. Overview of (left column) fitted functions, (second column) soil moisture memory, (third column) its uncertainty (refer to text for details), (fourth column) $\tilde{\kappa}_{n}=\sigma_{w_{n, y}} / \sigma_{P_{n, y} t_{\text {lag }}}$, and (right column) $\rho\left(w_{n}, P_{n}\right)$ [as described in section $\left.4 \mathrm{~d}(1)\right]$ for all catchments going from (top row) high soil moisture memory to (bottom row) low soil moisture memory. In the left column, the red curves correspond to the fitted runoff ratio functions, the black lines show the fitted ET ratio functions, and the vertical blue lines denote the 5\% and $95 \%$ quantile of all soil moisture values in the time frame between April and October. Soil moisture memory, its uncertainty, $\tilde{\kappa}_{n}$, and $\rho\left(w_{n}, P_{n}\right)$ are computed for all months between April and October and for lag times between 5 and 40 days.

OS12 can be simplified to yield $\rho\left(w_{n}, P_{n}\right)$. High values of either of these controls are indicative of higher soil moisture memory. The first control, $\tilde{\kappa}_{n}$, reflects the size of the anomaly to be erased relative to that of the precipitation available to erase it, and the second describes how the effect of the precipitation may be diminished if its magnitude is not independent of the initial anomaly.

The fourth and fifth columns of Fig. 6 illustrate the values of these controls at all catchments for all months and lags considered. The ratio of the soil moisture and precipitation variabilities decreases from top to bottom in both figures as the soil moisture memory decreases, suggesting a connection. Confirming the results of OS12, comparatively high correlations between initial soil moisture and the subsequent precipitation (a reflection, indeed, of memory in precipitation itself) also seem to coincide with high memory in most catchments.

Moreover, these two figures show that the runoff optimization approach (section $2 \mathrm{~b}$ ) yields functions of similar shape for nearby catchments (e.g., Mentue/Broye and Sitter/Goldach), underlining the robustness of the simple model approach. However, despite such similarity in the functions, we can sometimes find different strengths for the soil moisture memory, as in the Mentue 

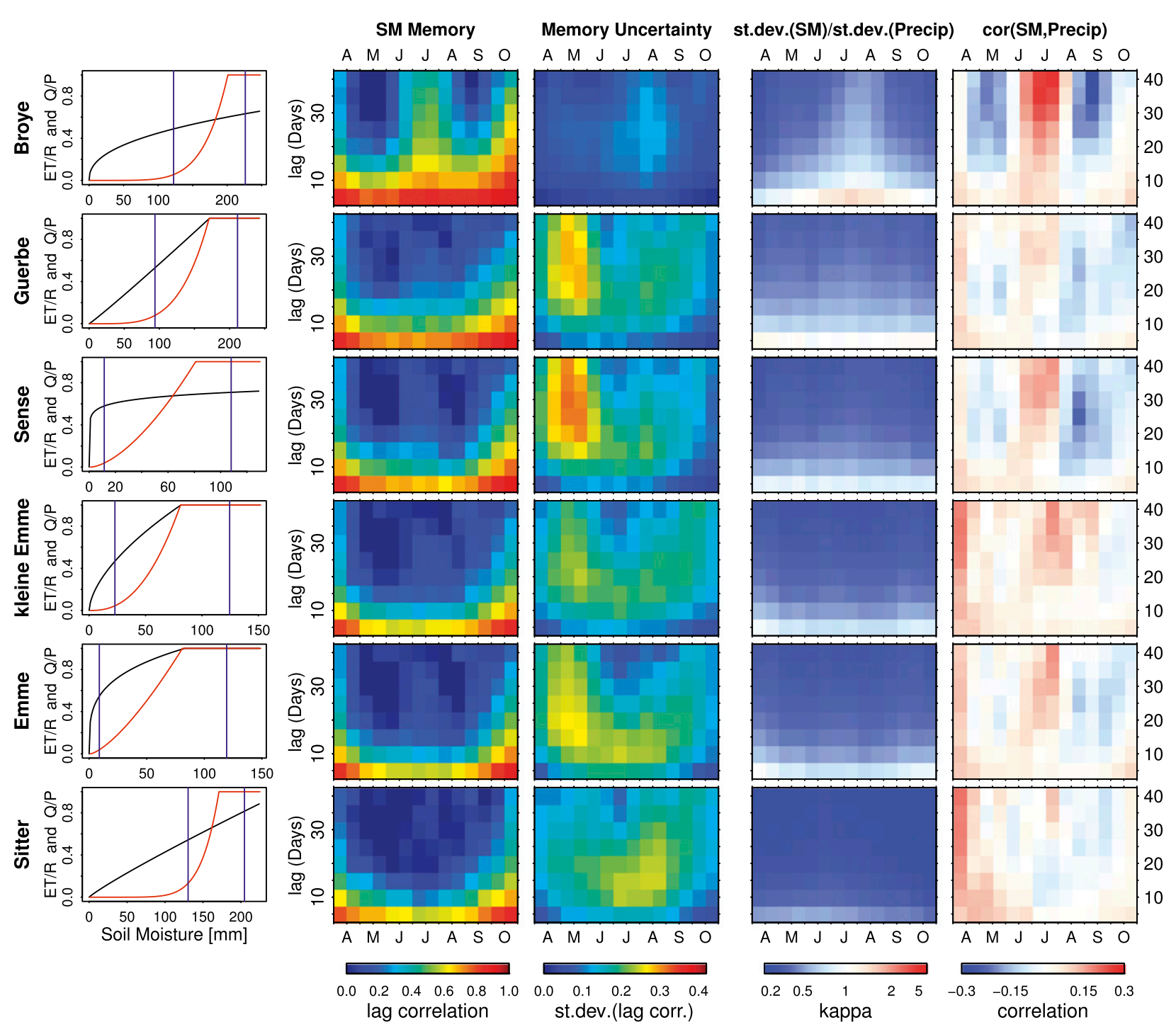

FIG. 6. (Continued)

and Broye catchments, illustrating the importance of catchment-specific parameters such as water-holding capacity and maximum ET ratio.

Figure 7 shows the correlations between the optimized model parameters and the resulting soil moisture memory (as shown in Fig. 5). Water-holding capacity is seen to be a strong control of soil moisture memory, which is intuitively sensible; it has a direct impact on the numerator of the standard deviation ratio discussed above. A second control of memory is the runoff ratio exponent (even if of questionable statistical significance because of the relatively small set of catchments). The higher this exponent, the greater the contrast in the impact of runoff on soil moisture in wet and dry conditions. That is, for a high exponent, the dampening impact of runoff on soil moisture anomalies is significantly reduced in drier conditions. OS12 found that especially dry anomalies contribute to a higher soil moisture memory, which explains why the runoff ratio exponent has such a large effect. It is important to note that these three controls are not statistically independent, because they would otherwise explain too much of the variance of soil moisture memory; a proper breakdown of the roles of these parameters and how they vary with each other would require a substantially larger collection of analyzed catchments.

\section{2) DEPENDENCE OF SOIL MOISTURE MEMORY ON ALTITUDE, TOPOGRAPHY, AND DRYNESS INDEX}

Investigating the dependency of soil moisture memory on altitude, topography, and dryness index allows us to separate the effects of soil and vegetation characteristics, 


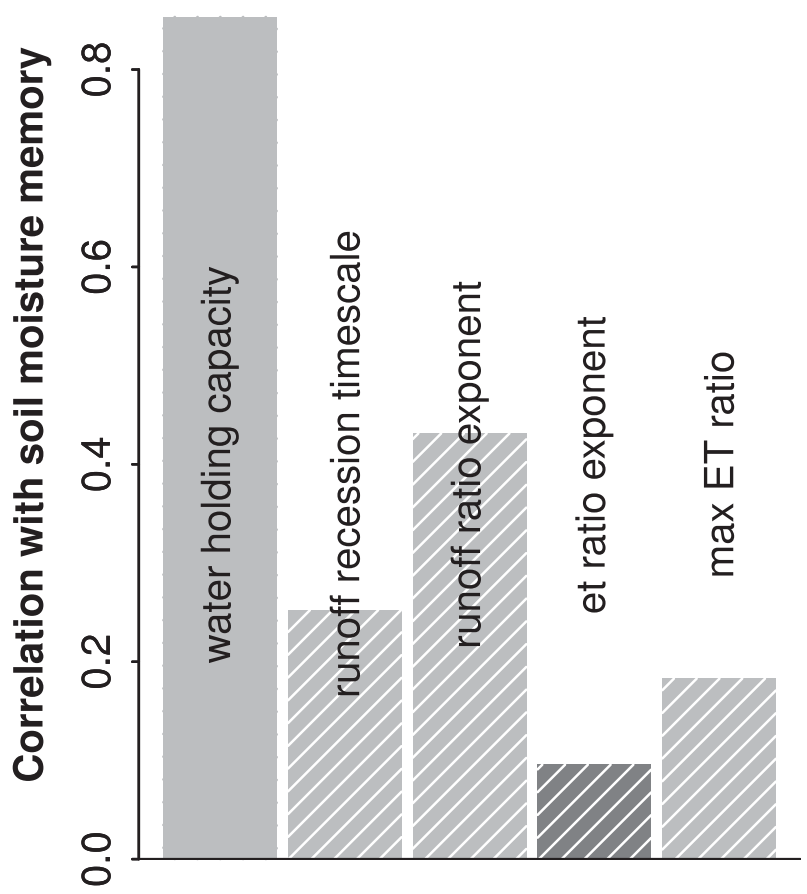

FIG. 7. Correlations of fitted model parameters (listed in Table 1) at all catchments with respective soil moisture memory at a lag of 30 days. Dark gray corresponds to negative correlations, and light gray indicates positive correlations. Hatching indicates correlations that are not significant on the $5 \%$ level (two-sided $t$ test).

morphology, and atmospheric forcing, respectively. Even if altitude and topography are usually related, here they are to some extent independent because of the complex (pre)alpine terrain of Switzerland. The top row of Fig. 8 demonstrates that memory decreases with altitude and with increased topography (expressed as CTI; see section $3 b$ ). The bottom row of the figure shows a link between $\tilde{\kappa}_{n}$ [the aforementioned ratio of initial soil moisture variability to precipitation variability shown in Eq. (10)] and both altitude and topography. This $\tilde{\kappa}_{n}$ ratio was identified in section $4 \mathrm{~d}(1)$ as a main control of soil moisture memory, which is consistent with the shown dependencies on altitude and topography. The higher (or hillier) a catchment is, the thinner the soil should be, leading to a decreased water-holding capacity and therefore a lower $\sigma_{w_{n}}$ and a lower $\tilde{\kappa}_{n}$ value. Even if topography and altitude are found to have the same impact on soil moisture memory, the reasons may not be the same, since topography as such only impacts soil moisture dynamics whereas altitude also reflects the varying atmospheric forcing [e.g., precipitation (variability) increasing with altitude and thereby reducing soil moisture memory as described in the previous subsection].

We also investigated the link between mean soil moisture memory (as shown in Fig. 5) and catchment-specific dryness index, as illustrated with the plots on the righthand side of Fig. 8. The dryness index is computed as $\bar{R} / \lambda \rho_{w} \bar{P}$, where $\lambda$ is the latent heat of vaporization and $\bar{R}$ and $\bar{P}$ are long-term averages of annual net radiation and precipitation, respectively. Soil moisture memory tends to increase with increasing dryness index, even if the diagnosed relationship between the two is rather weak. Less precipitation leads to a lower variability and thus a higher $\tilde{\kappa}_{n}$ value, as shown in the figure.

Comparing the influence of these three controls on soil moisture memory in Switzerland as indicated by the $R^{2}$ values, we find that altitude is of highest importance, followed by topography and dryness index.

\section{Conclusions}

In this study, we modified the simple water balance model proposed by Koster and Mahanama (2012) to include such features as streamflow recession and an implicit form of the water balance equation. We then applied the model to the analysis of soil moisture memory. Our main tested hypothesis was whether such a simple model can be used to extract information on soil moisture memory based on observations of precipitation, net radiation, and streamflow alone, since these observations are much more plentiful than soil moisture observations.

Our approach was successfully validated using data from some of the relatively rare catchments for which soil moisture measurements and contemporaneous meteorological measurements are adequate. Using only precipitation, net radiation, and streamflow data, the model captures the first-order behavior of the observed soil moisture memory in terms of its variation with season and the considered lag (Fig. 1). The model also reproduces the observed soil moisture anomalies reasonably well (Fig. 3).

We then used the validated model to estimate the soil moisture memory within 13 near-natural catchments across Switzerland. The resulting spatial distribution of estimated memory allowed an analysis of the controls on this memory. Our results support earlier propositions that the main controls of memory in central Europe are (i) the ratio of the standard deviations of initial soil moisture and subsequent precipitation and (ii) the correlation between the initial soil moisture and the subsequent precipitation. Soil moisture memory in the vicinity of the Alps appears to decrease with altitude and hilliness (as measured by CTI), possibly because soils at higher elevations tend to be thinner.

The study with the 13 Swiss catchments demonstrates that the simple water balance model can be used in conjunction with precipitation, net radiation, and streamflow 

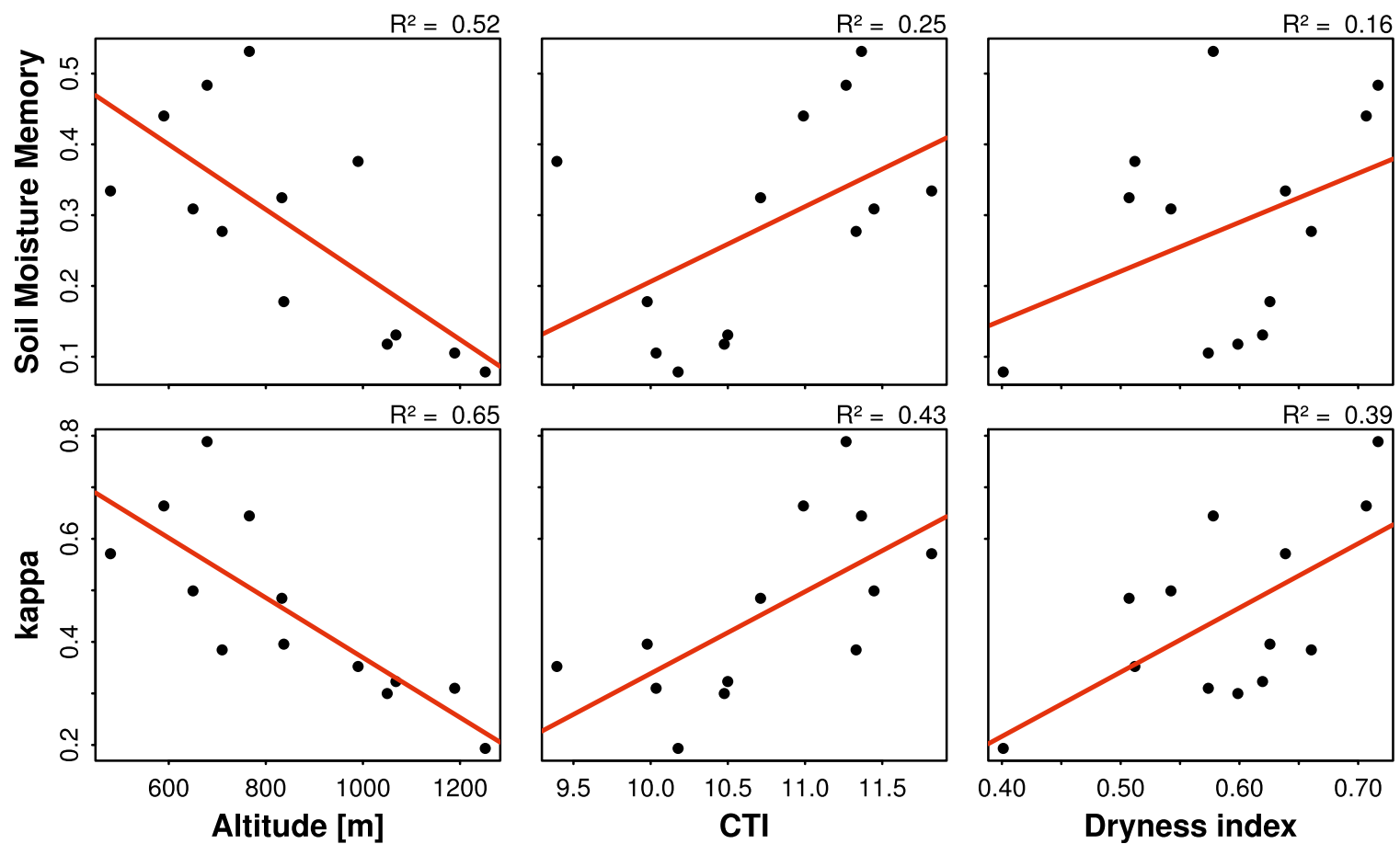

FIG. 8. (top) The soil moisture memories of lag 30 days of all 13 catchments plotted against altitude, CTI, and dryness index, including a least squares fit and explained fraction of variance. (bottom) As in the top row, but for the ratio $\tilde{\kappa}_{n}=\sigma_{w_{n, y}} / \sigma_{P_{n, y} t_{\text {lag }}}$.

measurements to estimate soil moisture memory and its controls even in the absence of direct soil moisture measurements. Applying this methodology to catchments in other regions of the world could help identify areas of strong soil moisture memory, that is, areas for which soil moisture initialization has a chance to contribute to hydrological or meteorological prediction.

Acknowledgments. We acknowledge the Swiss Federal Office for the Environment (FOEN) for providing streamflow data for the 13 Swiss catchments and the Swiss weather service (MeteoSwiss) for providing the corresponding precipitation data. We thank Massimiliano Zappa for sharing these data with us, as well as Guenther Seufert and Christoph Ammann for providing data from San Rossore and Oensingen, respectively. We also thank three anonymous reviewers for helpful comments on the manuscript and Gerd Vogel and Guenther Seufert for advice on the CEOP and Carboeurope databases, which we acknowledge for sharing the Falkenberg, Kehrigk, and San Rossore data, as well as the hydrological service of the Tuscany Region for providing the streamflow data of the Arno River. We acknowledge financial support from the Swiss National Foundation through the NRP61 DROUGHT$\mathrm{CH}$ project, as well as partial support from the EU-FP7 DROUGHT-RSPI project.

\section{APPENDIX}

\section{Optimization Procedure for Identification of Catchment-Specific Parameter Sets}

We first choose a random value for each parameter in Eqs. (2) and (6) from within a prescribed acceptable range and add a prescribed step width (see Table 1) to yield a second value for each parameter. We then run the model for all $2^{5}=32$ combinations of parameters to find the set which yields the highest correlation between modeled and observed streamflow. After that, we rerun the model using another $2^{5}=32$ combinations, assigning to each parameter the optimal value found before and this value with the respective step width subtracted (if the lower value from before was the optimal value) or added (if the higher value from before was the optimal value). This procedure is repeated until the same set of parameters is found two times in a row.

This procedure, of course, guarantees only a local (rather than a global) optimum in the five-dimensional parameter space. We thus repeat the procedure 20 times, always starting with new randomly chosen values for each parameter. This yields 20 local optima, of which many are similar or even identical, underlining the robustness of this approach. Of these 20 local optima, we take the best as our parameter set for a given catchment. Our tests with the 
procedure suggest that higher computational effort would probably not yield a different solution; given the step widths applied to the parameters, we most likely indeed find the global optimum in the five-dimensional parameter space.

\section{REFERENCES}

Ammann, C., O. Marx, V. Wolff, and A. Neftel, 2010: Measuring the biosphere-atmosphere exchange of total reactive nitrogen by eddy covariance using a novel converter. Preprints, 29th Conf. on Agricultural and Forest Meteorology, Keystone, CO, Amer. Meteor. Soc., 8.1. [Available online at https://ams. confex.com/ams/pdfpapers/172693.pdf.]

Baldocchi, D. D., and Coauthors, 2001: FLUXNET: A new tool to study the temporal and spatial variability of ecosystemscale carbon dioxide, water vapor and energy flux densities. Bull. Amer. Meteor. Soc., 82, 2415-2435, doi:10.1175/ 1520-0477(2001)082<2415:FANTTS $>2.3$.CO;2.

Dorigo, W. A., and Coauthors, 2011: The international soil moisture network: A data hosting facility for global in situ soil moisture measurements. Hydrol. Earth Syst. Sci., 15, 16751698, doi:10.5194/hess-15-1675-2011.

Douville, H., 2010: Relative contribution of soil moisture and snow mass to seasonal climate predictability: A pilot study. Climate Dyn., 34, 797-818, doi:10.1007/s00382-008-0508-1.

Entin, J. K., A. Robock, K. Y. Vinnikov, S. E. Hollinger, S. Liu, and A. Namkhai, 2000: Temporal and spatial scales of observed soil moisture variations in the extratropics. J. Geophys. Res., 105, 11 865-11877, doi:10.1029/2000JD900051.

Foken, T., F. Wimmer, M. Mauder, C. Thomas, and C. Liebethal, 2006: Some aspects of the energy balance closure problem. Atmos. Chem. Phys., 6, 4395-4402, doi:10.5194/acp-6-4395-2006.

Franssen, H. H., R. Stöckli, I. Lehner, E. Rotenberg, and S. I. Seneviratne, 2010: Energy balance closure of eddy covariance data: a multi-site analysis for European FLUXNET stations. Agric. For. Meteor., 150, 1553-1567, doi:10.1016/ j.agrformet.2010.08.005.

Hirschi, M., and Coauthors, 2011: Observational evidence for soilmoisture impact on hot extremes in southeastern Europe. Nat. Geosci., 4, 17-21, doi:10.1038/ngeo1032.

Kirchner, J., 2009: Catchments as simple dynamical systems: Catchment characterization, rainfall-runoff modeling, and doing hydrology backward. Water Resour. Res., 45, W02429, doi:10.1029/2008WR006912.

Koster, R. D., and M. J. Suarez, 2001: Soil moisture memory in climate models. J. Hydrometeor., 2, 558-570, doi:10.1175/ 1525-7541(2001)002<0558:SMMICM $>2.0 . \mathrm{CO} ; 2$.

— droclimatic means and variability. J. Hydrometeor., 13, 16041620, doi:10.1175/JHM-D-12-050.1.

_- and Coauthors, 2004: Regions of strong coupling between soil moisture and precipitation. Science, 305, 1138-1140, doi:10.1126/ science.1100217.

_ S. P. P. Mahanama, B. Livneh, D. P. Lettenmaier, and R. H. Reichle, 2010a: Skill in streamflow forecasts derived from large-scale estimates of soil moisture and snow. Nat. Geosci., 3, 613-616, doi:10.1038/ngeo944.

zation to subseasonal forecast skill: First results from a multimodel experiment. Geophys. Res. Lett., 37, L02402, doi:10.1029/ 2009GL041677.
Mahanama, S. P. P., B. Livneh, R. D. Koster, D. Lettenmaier, and R. Reichle, 2012: Soil moisture, snow, and seasonal streamflow forecasts in the United States. J. Hydrometeor., 13, 189-203, doi:10.1175/JHM-D-11-046.1.

Mittelbach, H., and S. I. Seneviratne, 2012: A new perspective on the spatio-temporal variability of soil moisture: Temporal dynamics versus time invariant contributions. Hydrol. Earth Syst. Sci., 16, 2169-2179, doi:10.5194/hess-16-2169-2012.

Moore, I. D., P. E. Gessler, G. A. Nielsen, and G. A. Petersen, 1993: Terrain attributes: Estimation methods and scale effects. Modelling Change in Environmental Systems, A. J. Jakeman, M. B. Beck, and M. J. McAleer, Eds., Wiley, 189-214.

Mueller, B., and S. I. Seneviratne, 2012: Hot days induced by precipitation deficits at the global scale. Proc. Natl. Acad. Sci. USA, 109, 12398-12 403, doi:10.1073/pnas.1204330109.

Orth, R., and S. I. Seneviratne, 2012a: Analysis of soil moisture memory from observations in Europe. J. Geophys. Res., 117, D15115, doi:10.1029/2011JD017366.

$\longrightarrow$, and,$- 2012 \mathrm{~b}$ : Propagation of soil moisture memory to runoff and evapotranspiration. Hydrol. Earth Syst. Sci. Discuss., 9, 12103-12 143, doi:10.5194/hessd-9-12103-2012.

Robock, A., K. Y. Vinnikov, G. Srinivasan, J. K. Entin, S. E. Hollinger, N. A. Speranskaya, S. Liu, and A. Namkhai, 2000: The global soil moisture data bank. Bull. Amer. Meteor. Soc., 81, 1281-1299, doi:10.1175/1520-0477(2000)081<1281:TGSMDB > 2.3.CO;2.

Seneviratne, S. I., and R. D. Koster, 2012: A revised framework for analyzing soil moisture memory in climate data: Derivation and interpretation. J. Hydrometeor., 13, 404-412, doi:10.1175/ JHM-D-11-044.1.

_ ulations: Analysis of Global Land-Atmosphere Coupling Experiment (GLACE) data. J. Hydrometeor., 7, 1090-1112, doi:10.1175/JHM533.1.

— , T. Corti, E. L. Davin, M. Hirschi, E. B. Jaeger, I. Lehner, B. Orlowsky, and A. J. Teuling, 2010: Investigating soil moistureclimate interactions in a changing climate: A review. Earth Sci. Rev., 99, 125-161, doi:10.1016/j.earscirev.2010.02.004.

_ , and Coauthors, 2012: Swiss prealpine Rietholzbach research catchment and lysimeter: 32 year time series and 2003 drought event. Water Resour. Res., 48, W06526, doi:10.1029/ 2011WR011749.

Teuling, A. J., I. Lehner, J. W. Kirchner, and S. I. Seneviratne, 2010a: Catchments as simple dynamical systems: Experience from a Swiss prealpine catchment. Water Resour. Res., 46, W10502, doi:10.1029/2009WR008777.

_ - and Coauthors, 2010b: Contrasting response of European forest and grassland energy exchange to heatwaves. Nat. Geosci., 3, 722-727, doi:10.1038/ngeo950.

Tirone, G., 2003: Stima del bilanco del carbonio di due ecosistemi forestali Mediterranei. Confronto tra una lecceta e una pineta (in Italian). Ph.D. thesis, University of Tuscia, $98 \mathrm{pp}$.

Twine, T. E., and Coauthors, 2000: Correcting eddy-covariance flux underestimates over a grassland. Agric. For. Meteor., 103, 279300, doi:10.1016/S0168-1923(00)00123-4.

Vinnikov, K. Y., and I. B. Yeserkepova, 1991: Soil moisture: Empirical data and model results. J. Climate, 4, 66-79, doi:10.1175/ 1520-0442(1991)004<0066:SMEDAM > 2.0.CO;2.

Viterbo, P., and A. K. Betts, 1999: Impact of the ECMWF reanalysis soil water on forecasts of the July 1993 Mississippi flood. J. Geophys. Res., 104, 19361-19366, doi:10.1029/1999JD900449.

Wilson, K., and Coauthors, 2002: Energy balance closure at FLUXNET sites. Agric. For. Meteor., 113, 223-243, doi:10.1016/ S0168-1923(02)00109-0. 